\title{
EFFECT OF FISH OIL AND ANIMAL FAT SUPPLEMENTATION ON LIPID FRACTIONS AND THYROID HORMONES IN ADULT MALE RATS
}

\author{
El-Ayadi D. El-Abed \\ GIT (liver and metabolic diseases), Faculty of Public Health, Zawia University, Libya. \\ ABSTRACT
}

Epidemiological studies have demonstrated that n-3 polyunsaturated fatty acid (PUFA) consumption is associated with a reduced risk of atherosclerosis and hyperlipidemia. It is well known that lipid metabolism is also influenced by thyroid hormones. The aim of the current study was to test whether fish oil versus beef fat supplementation would affect lipid metabolism in correlation with thyroid hormones in adult male rats. In this investigation, dietary lipids (fish oil) and (beef fat) were fed to adult male albino rats. Both dietary lipids were fed in concentration of $27 \%$ and $45 \%$ of the diet's dry matter, for 14 days. At the end of the experiment, the animals were sacrificed; the plasma and liver fractions including cholesterol, triglycerides, high and low density lipoprotein were measured biochemically; and the plasma levels of $\mathrm{T}_{3}$ and $\mathrm{T}_{4}$ were determined using RIA. The results revealed the following: (a) the fish oil diets decreased the plasma lipid fractions, except the high density lipoprotein which was increased, while the beef fat diets increased the plasma lipid fractions except the high density lipoprotein which was decreased. (b) the beef fat diets increased the liver lipid fractions more than the fish oil diets. (c) the $T_{4}$ levels showed non significant change . (d) the plasma $T_{3}$ levels revealed a significant increase in the animal groups fed the diets containing $27 \%$ of either fish oil or beef fat. These results suggested that fish oil has a hypolipidemic effect while beef fat has a hyperlipidemic effect. Furthermore, the influence of lipid calories on the plasma $\mathrm{T}_{3}$ levels may be more pronounced than that of carbohydrate when a normal amount of carbohydrate was ingested.

\section{INTRODUCTION}

E vidence from multiple research paradigms, including in vitro studies, animal experiments, observational studies, and clinical trials, supported the cardiovascular benefits of long-chain poly unsaturated fatty acids ( $\omega-3$ PUFAs), especially for fatal cardiovascular disease (CVD) events [1]. Of particular note are the n-3 PUFA: eicosapentaenoic acid [EPA, 20:5 n-3] and docosahexaenoic acid (DHA, 22:6 n-3) [2]. Fish are the major food sources of DHA and EPA and are carried in the circulation as triglycerides, especially phospholipids [3]. There are several experimental studies showed that the n-3 PUFA perform several functions in relation to the structure and function of the membrane, tissue metabolism, and gene regulation [4]. These fatty acids play important roles in reducing hypertriglyceridaemia [5], low density lipoprotein cholesterol (LDLc), very low density lipoprotein cholesterol (VLDLc), and increasing high density lipoprotein cholesterol (HDLc) concentrations [6] as well as various components of these molecules e.g. ApoA1 and ApoB100 of HDL and LDL/VLDL respectively. EPA and DHA improve hypertension [7], insulin sensitivity and glycaemia [8].

Moreover, it is well established that dyslipidaemia is one of the major risk factors for atherosclerosis, in particular CAD, cerebrovascular disease and peripheral vascular disease [9]. In particular, it is well established that there is a causal link between atherosclerosis and elevated plasma concentrations of total cholesterol and elevated plasma LDL concentration [10]

Nakatani et al [11] reported that the liver plays an important role in lipid homeostasis and might be influenced by disturbance in $\omega-6: \omega-3$ PUFA ratio. In mice, $\omega-3$ PUFAs alleviated liver inflammation. Moreover pretreatment with $\omega-3$ PUFAs significantly decreased the extent of microcirculatory failure which followed ischemia. Perfusion injury and protect against hepatocellular damage in the macrosteatotic mice liver. The metabolic changes caused by dietary fat are regulated at the level of gene expression because lipid regulated transcription factors such as PPARs, sterol regulatory element binding protein SREBP1C [12]. PPARs are fatty acid regulated nuclear hormone receptors that could control lipid oxidation [13].

Thyroid hormones affect reactions in almost all pathways of lipid metabolism (14). $\omega-3$ PUFAs present in fish oil potently decrease serum lipids, which is also an effect of thyroid hormones [15]. Both PUFAs and thyroid hormones affect hepatic lipid metabolism, and it has been hypothesized that a long-term diet rich in $\omega-3$ PUFAs would enhance thyroid hormone action in the liver [16]. However, it has been reported that high consumption of fish carries a lower risk of CVD as a consequence of 
dietary $\omega-3$ PUFA; especially (EPA) and (DHA) content. A controversy exists about the component/s responsible of these beneficial effects and, in consequence, which is the best proportion between both fatty acids [2]. Clearly therefore, the aim of the present study was: firstly, to examine the effect of dietary fish oil (polyunsaturated fat) and beef fat (saturated fat) on some lipid fractions in both plasma and liver; secondly, to examine the effect of caloric content of the diets containing these lipids on the plasma levels of $\mathrm{T}_{3}$ and $\mathrm{T}_{4}$ in adult male rats.

\section{MATERIALS AND METHODS}

Mature male albino rats weighing $200 \mathrm{~g}$ were used in this study. They were divided into five groups, ten animals each which were housed in five cages. The $1^{\text {st }}$ group fed on a control diet; the $2^{\text {nd }}$ and the $3^{\text {rd }}$ groups fed on diets containing two levels of beef fat, and the $4^{\text {th }}$ and $5^{\text {th }}$ groups fed on diets containing two levels of fish oil (table 1). The experimental diets were prepared from natural ingredients as fish meal and wheat bran and were analyzed to calculate the protein, lipid and carbohydrate percentages in each diet. Then, the caloric content in each diet was calculated according to the physiological fuel of 4.0, 9.0 and 4.0 for protein, fat and carbohydrate respectively. The experimental animals were fed on experimental diets for two weeks.

Table (1): Diets formulation and composition

\begin{tabular}{lccccc}
\hline Dry diet ingredients (g) & G I (control) & G II & G III & GIV & G V \\
\hline Fish meal & 24 & 27 & 30 & 27 & 30 \\
\hline Wheat bran & 65 & 42 & 20 & 2 & 20 \\
\hline Fish oil & - & - & - & 20 & 20 \\
\hline Beef fat & 4 & 24 & 43 & - & - \\
\hline Vitamins and mineral mixtures & 7 & 7 & 7 & 7 & 7 \\
\hline Total grams & 100 & 100 & 100 & 100 & 100 \\
\hline Calculated protein & 21.45 & 21.3 & 21.3 & 21.3 & 21.3 \\
\hline Calculated lipids & 7.2 & 27 & 45.8 & 27 & 45.8 \\
\hline Calculated carbohydrate \% & 64.35 & 44.7 & 25.9 & 44.7 & 25.3 \\
\hline Calculated caloric content & 408 & 507 & 601 & 507 & 601 \\
\hline
\end{tabular}

At the end of the experiment, the animals were sacrificed and the plasma obtained from the collected blood were stored at $-20{ }^{\circ} \mathrm{C}$ till analyzed. The lipids were extracted from the livers according to Kates [17] and stored at $-20{ }^{\circ} \mathrm{C}$ till analyzed. The total cholesterol (TC) concentrations were determined according to Allain et al [18], triglycerides (TG) according to Wieland [19], high density lipoprotein-cholesterol (HDL-C) according to Finaley [20], and low density lipoprotein cholesterol (LDL-C) according to Friedewald et al [21). The $T_{3}$ and $T_{4}$ were determined using RIA technique according to Abraham [22). The results were statistically analyzed using analysis of variance (ANOVA), F-test according to Snedecor and Cochran [23] and Duncan's multiple-range test according to Duncan [24].

\section{RESULTS}

The mean plasma concentrations of cholesterol $(\mathrm{mg} / \mathrm{dl})$, triglycerides $(\mathrm{mg} / \mathrm{dl})$, HDL-cholesterol (mg/dl), LDL-cholesterol (mg/dl), $\mathrm{T}_{3}(\mathrm{ng} / \mathrm{dl})$ and $\mathrm{T}_{4}$ $(\mathrm{mg} / \mathrm{dl})$ are presented in table 2 . The hepatic lipid fractions concentration are presented in table 3.

\section{Plasma lipid fractions:}

The cholesterol concentration showed significant increase of $64 \%$ in the $3^{\text {rd }}$ group while the $5^{\text {th }}$ group revealed a decrease of $40 \%$ less than the control group. The triglycerides indicated an increase of $33 \%$ and $51 \%$ in the $2^{\text {nd }}$ and $3^{\text {rd }}$ groups respectively and showed a decrease of $24 \%$ and $28 \%$ in the $4^{\text {th }}$ and $5^{\text {th }}$ groups orderly. HDL-cholesterol indicated a decrease of $32 \%$ in the $3^{\text {rd }}$ group but showed $46 \%$ and $10.7 \%$ increase in the $4^{\text {th }}$ and $5^{\text {th }}$ groups respectively. The LDL-cholesterol indicated an increase of $52 \%$ in the $3^{\text {rd }}$ group, while showed a decrease of $32 \%$ in the $5^{\text {th }}$ group.

\section{Plasma $\mathbf{T}_{3}$ and $\mathbf{T}_{4}$ :}

The plasma $\mathrm{T}_{3}$ showed an increase of $43 \%$ and $55 \%$ in the $2^{\text {nd }}$ and $4^{\text {th }}$ groups, while plasma $\mathrm{T}_{4}$ levels did not show a significant changes.

\section{The hepatic lipid fractions:}

There was a proportional increase in the hepatic lipid fractions with the increase of the dietary lipids intakes. The cholesterol concentrations revealed a significant increase of $25 \%, 51 \%, 11 \%$ and $20 \%$ in the $2 \mathrm{nd}, 3 \mathrm{rd}$, 4th and 5th groups respectively. The triglycerides showed, in the same respective groups, an increase of $11 \%, 28 \%, 14 \%$ and $31 \%$. HDL- 
cholesterol indicated $33 \%, 63 \%, 75 \%$ and $78 \%$ increase in the same consecutive groups. LDL- cholesterol showed in the same previous orderly groups and increase of $10 \%, 24 \%, 18 \%$ and $33 \%$.

Table (2): Plasma lipid fraction concentrations and $T_{3}$ and $T_{4}$ levels in rats fed beef fat and fish oil for two weeks.

\begin{tabular}{|c|c|c|c|c|c|}
\hline & G I (control) & G II & G III & G IV & G V \\
\hline TC (mg/dl) & $85.8^{\mathrm{a}} \pm 6.4$ & $110.3^{\text {ab }} \pm 9.3$ & $140.6^{\mathbf{b}} \pm 12.7$ & $72.6^{\mathbf{a c}} \pm 5.3$ & $51.8^{\mathrm{c}} \pm 3.8$ \\
\hline TG (mg/dl) & $190.7^{a} \pm 10.8$ & $260.3^{b} \pm 15.3$ & $290.7^{\mathbf{b}} \pm 20.8$ & $160.3^{\mathfrak{c}} \pm 8.8$ & $151.6^{\mathbf{c}} \pm 10.3$ \\
\hline HDL-C (mg/dl) & $27.6^{\mathrm{a}} \pm 1.8$ & $25.3^{\mathbf{a b}} \pm 2.3$ & $18.8^{\mathrm{b}} \pm 1.5$ & $40.2^{c} \pm 2.4$ & $57.2^{\mathrm{c}} \pm 4.3$ \\
\hline LDL-C (mg/dl) & $46.9^{\mathrm{a}} \pm 2.3$ & $58.1^{\mathrm{ab}} \pm 3.6$ & $71.3^{\mathrm{b}} \pm 5.3$ & $38.6^{\mathbf{a c}} \pm 2.1$ & $31.7^{\mathbf{c}} \pm 1.9$ \\
\hline $\mathrm{T} 3$ (ng/dl) & $23.8^{\mathrm{a}} \pm 1.6$ & $34.0^{\mathbf{b}} \pm 2.3$ & $20.1^{\mathrm{a}} \pm 1.8$ & $37.0^{\mathbf{b}} \pm 2.6$ & $20.0^{\mathrm{a}} \pm 1.9$ \\
\hline $\mathrm{T} 4(\mu \mathrm{g} / \mathrm{dl})$ & $11.3^{\mathrm{a}} \pm 1.4$ & $11.1^{\mathrm{a}} \pm 1.2$ & $10.9^{\mathrm{a}} \pm 1.3$ & $11.3^{\mathrm{a}} \pm 1.1$ & $11.0^{\mathrm{a}} \pm 1.5$ \\
\hline
\end{tabular}

Means \pm S.E; a,b,c = Means in the same rows sharing the same superscript are not significantly different from each other at $\mathrm{P}<0.05$; and Choles. refers to total cholesterol

Table (3): Hepatic lipid fraction concentrations in male rats fed animal fat and fish oil for two weeks.

\begin{tabular}{cccccc}
\hline & G I (control) & G II & G III & G IV & G V \\
\hline $\begin{array}{c}\text { TC } \\
(\mathrm{mg} / 100 \mathrm{~g})\end{array}$ & $252.6^{\mathbf{a}} \pm 10.1$ & $314.8^{\mathbf{b}} \pm 15.3$ & $380.7^{\mathbf{c}} \pm 20.3$ & $280.4^{\mathbf{a b}} \pm 20.1$ & $302.0^{\mathbf{b}} \pm 17.8$ \\
\hline $\begin{array}{c}\text { TG } \\
(\mathrm{mg} / 100 \mathrm{~g})\end{array}$ & $290.3^{\mathbf{a}} \pm 17.3$ & $320.8^{\mathbf{a}} \pm 25.6$ & $370.8^{\mathbf{b}} \pm 30.4$ & $330.6^{\mathbf{a}} \pm 21.6$ & $380.6^{\mathbf{c b}^{\mathbf{b}} \pm 20.3}$ \\
\hline $\begin{array}{c}\text { HDL-C } \\
(\mathrm{mg} / 100 \mathrm{~g})\end{array}$ & $80.3^{\mathbf{a}} \pm 7.8$ & $106.7^{\mathbf{a b}} \pm 8.1$ & $130.8^{\mathbf{b c}} \pm 7.6$ & $140.8^{\mathbf{b c}} \pm 8.8$ & $142.8^{\mathbf{b c}} \pm 7.1$ \\
\hline $\begin{array}{c}\text { LDL-C } \\
(\mathrm{mg} / 100 \mathrm{~g})\end{array}$ & $163.8^{\mathbf{a}} \pm 10.1$ & $180.7^{\mathbf{a b}} \pm 10.3$ & $203.6^{\mathbf{b}} \pm 10.8$ & $193.6^{\mathbf{a b}} \pm 11.8$ & $218.6^{\mathbf{b}} \pm 15.3$ \\
\hline
\end{tabular}

Means \pm S.E.; a,b,c $=$ Means in the same rows sharing the same superscript are not significantly different from each other at $\mathrm{P}<0.05$.

Figure 1: Plasma lipid fraction concentrations levels in rats fed beef fat and fish oil for two weeks.

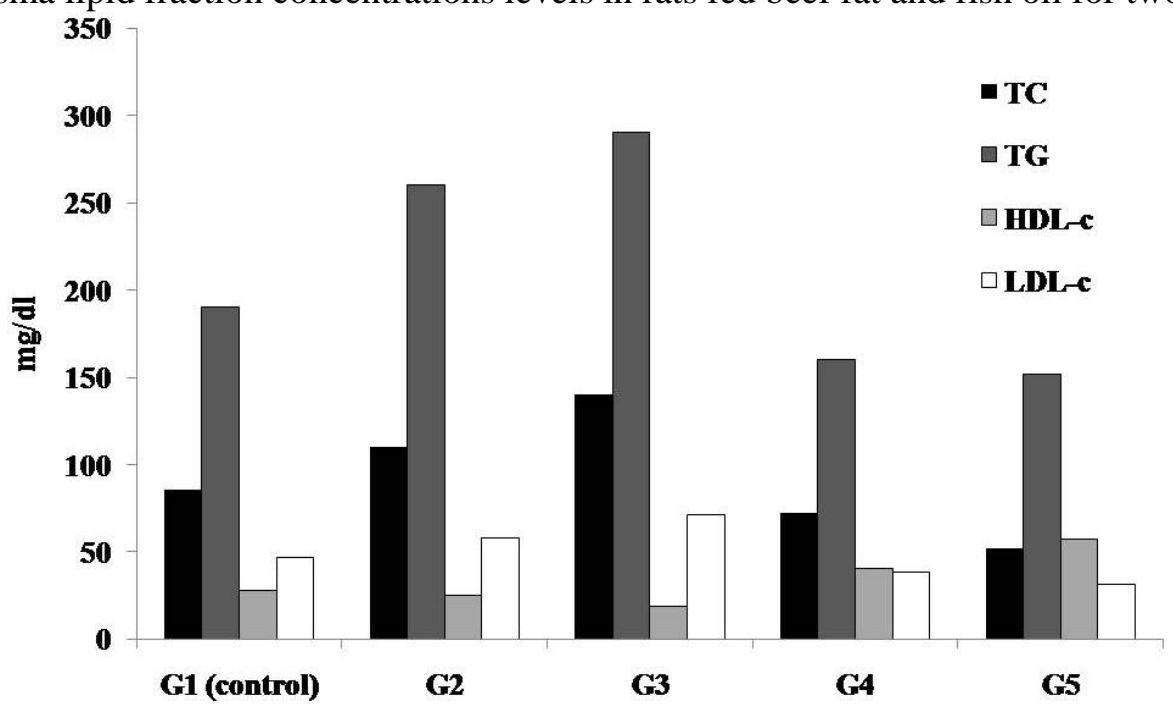


Figure 2: Plasma $T_{3}$ and $T_{4}$ levels in rats fed beef fat and fish oil for two weeks.

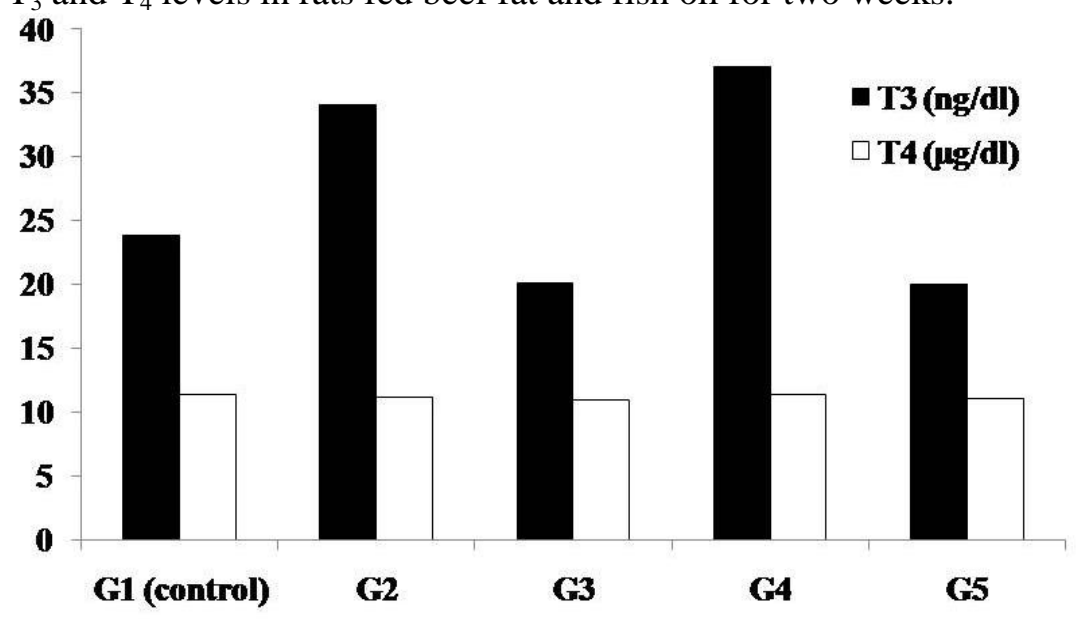

Figure 3: Hepatic lipid fraction concentrations in male rats fed animal fat and fish oil for two weeks.

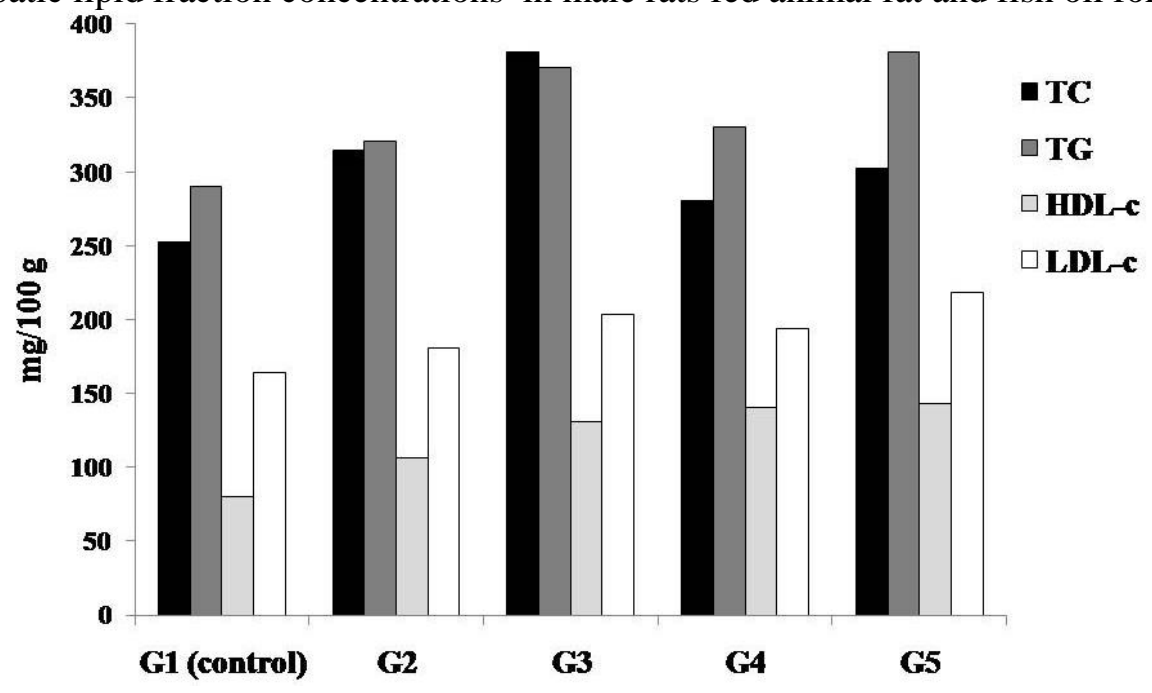

\section{DISCUSSION}

Cardiovascular disease is one of the major health problems in the world. It is dramatically increasing in the last 10 years [25]. Blood lipid profile determines the risk of cardiac disease. Lipid profile includes TC, HDL-C (often called good cholesterol), LDL-C (often called bad cholesterol) and TG [26]. Hyperlipidemia remains the strongest risk factor for CVD. Prevention of CVD risk factors such as obesity and dyslipidemia has been an important challenge in developing countries [26]. CVD is a major health problem in the world resulting in premature morbidity and mortality since it has been reported that high intake of cholesterol induces multiple cardiac complications including coronary heart disease and stroke [27].

The results of the current study demonstrated the effect of dietary fat saturation on both plasma and liver lipid fractions and lipoprotein. It would appear that the lipid fractions decreased in the group of animals fed fish oil (rich in $\omega$-PUFA) while increased in the groups of animals fed animal fat (rich in saturated fatty acids). These results are in agreement with a similar study of Foxall and Shwaery [28], who found that adhesion of platelets and lipid profile from swine fed fish oil was significantly lower than those fed butter fat. Moreover, Kawasaki et al [29] indicated that dietary fish oil and sulfur amino acid, L-methionine and L-cystine, have hypolipidemic effects in cancerrelated hyperlipidemia, and that the effects of these two factors on the decrease in these serum lipid concentrations are additive; these two factors may affect the lipid metabolism via different pathways and mechanisms. However, several mechanisms of action for the hypocholesterolemic effect of polyunsaturated fats and plant proteins has been suggested by Jackson et al [30] including: (1) increase fecal excretion of bile acids and/or neutral steroids, (2) decrease cholesterol absorption, (3) decrease cholesterol synthesis, (4) increase cholesterol deposition in body tissues and (5) 
altered lipoprotein structure and metabolism. Furthermore, Wong et al [31] concluded that the hypotriglyceridemia induced by fish oil feeding reflects; diminished lipogenesis; increase ketogenesis and fatty acd oxidation; as well as reduction in triglyceride secretion by the liver. However, the findings of Bravo et al [32] indicated that feeding rats mono- or $\mathrm{n}-6$ polyunsaturated as compared to saturated fat in the diet promotes the storage of cholesteryl ester in the liver and leads to increased bile acid synthesis, resulting in the more rapid excretion of cholesterol originating from the diet via the bile. Moreover, the results of Wong et al [33] suggested that the TG-lowering effect of $\omega-3$ FAEEs is associated with the decreased VLDL-TG secretion rate and hence lower plasma VLDL-TG concentration in obesity. Acute dietary n-3 PUFA dietary supplementation can improve fasting as well as postprandial lipid metabolism and components of the associated inflammatory response in the JCR:LA-cp rat. Further, moderate dose n-3 PUFA supplementation may reduce corresponding body weight during conditions of hypercholesterolaemia and/or modulate inflammation associated with obesity and the metabolic syndrome [34]

It would appear from the present study that the plasma $\mathrm{T}_{3}$ levels increased in groups of animals fed diets containing $27 \%$ lipids, $44.7 \%$ carbohydrates and 507 calories. However, these results partially contraindicated the results of Danforth et al [35] who indicated that under caloric-conditions in human subjects, replacement of dietary carbohydrate with fat for 3 weeks, was associated with decreased $T_{3}$ and increased reverse $T_{3}$ levels. When additional calories were added as carbohydrates, the $\mathrm{T}_{3}$ levels increased and the reverse $\mathrm{T}_{3}$ decreased. If the additional calories were given as a fat, the $T_{3}$ and reverse $T_{3}$ levels did not change. The present study and those of Davidson and Chopra [36], however, may not be directly comparable because of the different period of feeding the diet and the different proportion of carbohydrate, protein and lipids in the diets. Although increased lipid intake did not alter $\mathrm{T}_{3}$ levels as reported by Danforth et al [35], the $\mathrm{T}_{3}$ production rate were enhanced by dietary fat [37]. Moreover, Glade and Riimers [38] found a decrease in $\mathrm{T}_{4}$ and an increase of $\mathrm{T}_{3}$ levels in horse when fed diets containing $130 \%$ of their energy requirement, suggesting increased conversion of $\mathrm{T}_{4}$ to $T_{3}$. In addition Gavin and Moeler [39] showed that the increase in $\mathrm{T}_{3}$ levels after high carbohydrate meals, have been associated with accelerated peripheral conversion of $\mathrm{T}_{4}$ to $\mathrm{T}_{3}$ in rats. However, our results are consistent with the results of Davidson and Chopra [36] who suggested that non-carbohydrate as well as carbohydrate calorie sources are the important modulators of plasma $\mathrm{T}_{3}$ levels in man, moreover, the influence of noncarbohydrate calories may be more pronounced than that of carbohydrate when at least a normal amount of carbohydrate is ingested.

With respect the correlation between fish oil and thyroid function, the data of Souza et al [15] suggested that the increase in thyroid hormone signaling pathways in the liver may be one of the mechanisms by which $\omega-3$ PUFAs exert part of their effects on lipid metabolism. In addition, oral administration of EPA inhibited reduction of thyroid hormone levels and the change of thyroid follicles in induced hypothyroid rats. These findings suggested that FFA may affect thyroid functions and EPA may prevent induced hypothyroidism [14]

\section{REFERENCES}

1. Mozaffarian D. and Wu J.H.Y. (2011): Omega-3 fatty acids and cardiovascular disease: effects on risk factors, molecular pathways, and clinical events. J. M. Coll. Cardiol. 57: 1697-1699.

2. Laura L., Núria T., Mònica M., Vanesa S., Romeu M., and Giralt M. et al (2013): Protective effect of the omega-3 polyunsaturated fatty acids: Eicosapentaenoic acid/Docosahexaenoic acid 1:1 ratio on cardiovascular disease risk markers in rats. Lipids Health Dis. 12: 140.

3. Ackman R.G. (1989): Biogenic Lipids Fats and Oils. Boca Ratón. Florida: CRC Press.

4. Mozaffarian D., and Wu J.H. (2012): (n-3) fatty acids and cardiovascular health: are effects of EPA and DHA shared or complementary?. J. Nutr. 142: 614S-625S.

5. Aguilera A.A., Diaz G.H., Barcelata M.L., Guerrero O.A., Ros R.M. (2004): Effects of fish oil on hypertension, plasma lipids, and tumor necrosis factor-alpha in rats with sucrose induced metabolic syndrome. J. Nutr. Biochem. 15: 350-357.

6. Poudyal H., Panchal S.K., Diwan V., Brown L. (2011): Omega-3 fatty acids and metabolic syndrome: effects and emerging mechanisms of action. Prog. Lipid Res. 50(4): 372-387

7. Armitage J.A., Pearce A.D., Sinclair A.J., Vingrys A.J., Weisinger R.S., Weisinger H.S. (2003): Increased blood pressure later in life may be associated with perinatal n-3 fatty acid deficiency. Lipids. 38: 459-464. 
8. Sener A., Zhang Y., Bulur N., Louchami K., Malaisse W.J., Carpentier Y.A. (2009): The metabolic syndrome of omega3-depleted rats. II. Body weight, adipose tissue mass and glycemic homeostasis. Int. J. Mol. Med. 24: 125-129

9. Graham I., Atar D., Borch-Johnsen K., Boysen G., Burell G., Cifkova R., et al (2007): European guidelines on cardiovascular disease prevention in clinical practice: executive summary. Eur. Heart J. 28 (19): 2375-2414.

10.Mozaffarian, D. (2005): Does alpha-linolenic acid intake reduce the risk of coronary heart disease? A review of the evidence. Altern Ther Health Med.;11:24-30; quiz 31, 79.

11.Nakatani, T., Kim, H. and Ezaki, O. (2003) : A low fish oil inhibits SREBP-1 proteolytic cascade, while a high fish oil feeding decreases SREBP-1 mRNA in mice liver : relationship to antiobesity. J. Lipid. Research 144 : 369-379.

12.Shimomura, Y., Tamura, T., and Suzuki, M. (1990) : Less body fat accumulation in rats fed a safflower oil diet than in rats feed a beef tallow diet. J. Nutr. 120: 1291-1296.

13.Desvergne, B., and Wahli, W. (1999): Perixisome proliferator activatedreceptors nuclear control of Metabolism. Endocr. Rev. 20: 649-688.

14.Makino M., Oda N., Miura N., Imamura S., Yamamoto K., Kato T., Fujiwara K., Sawai Y., Iwase K., Nagasaka A., Itoh M. (2001): Effect of eicosapentaenoic acid ethyl ester on hypothyroid function. J. Endocrinol. 171(2): 259-265.

15.Souza L., Nunes M.O., Paula G.S., Cordeiro A., Penha-Pinto V., Neto J.F., Oliveira K.J., do Carmo M.d., Pazos-Moura C.C. (2010): Effects of dietary fish oil on thyroid hormone signaling in the liver. J. Nutr. Biochem. 21(10): 935-940.

16.Souza L.L.1., Cordeiro A., Oliveira L.S., de Paula G.S., Faustino L.C., Ortiga-Carvalho T.M., Oliveira K.J., Pazos-Moura C.C. (2011): Thyroid hormone contributes to the hypolipidemic effect of polyunsaturated fatty acids from fish oil: in vivo evidence for cross talking mechanisms. J Endocrinol. 1211(1): 6572.

17.Kates M. (1972): Techniques of lipidology. Isolation analysis and identification of lipids. Dept. Biochem., Attawa Univ., Attawa, Canada, pp. 361.

18.Allain C., Poon L., Chan C., Richmond W. and Fu P. (1974): Enzymatic determination of total cholesterol. Clin. Chem. 20: 470-475.
19.Wieland D. (1974): Methods of enzymatic analysis. Vol. 3, Acad. Press. Inc.

20.Finaley P. (1978): Determination of HDLcholesterol in plasma. Clin. Chem. 24: 931.

21.Friedewald W. et al. (1972): Determination of LDL-cholesterol in plasma. J. Endocrinology, 106: 21-25.

22.Abraham G.E. (1981): Radioassay systems in clinical endocrinology. Marcel Dekker, Inc., New York.

23. Snedecor G. and Cochran W. (1969): Statistical methods, 6th ed., Iowa State Univ., Press. Ames., IA.

24.Duncan D.B. (1955): Multiple-range and Multiple F-tests. Biometrics 11, 1-42.

25.Yamada M., Wong F.L., Kodama K., Sasaki H., Shimaoka K., Yamakido M. (1997): Longitudinal trends in total serum cholesterol levels in a Japanese cohort, 1958-1986. J. Clin. Epidemiol. 50:425-434.

26.Mustafizur R.; Pharm B.; and Pharm, R (2014): Hypocholesterolemic effects of fish and vegetable oils on the serum lipid profile of experimentally induced hypercholesterolemic rats. European Scientific J. 10: 1857 - 7881

27.Haddad F.H., Omari A.A., Shamailah Q.M., Malkawi O.M., Shehab A.I., Mudabber H.K., Shubaki M.K. (2002): Lipid profile in patients with coronary artery disease. Saudi Med. J. 23(9): 1054-1058.

28.Foxall T.L. and Shwaery G.T. (1990): Effects of dietary fish oil and butterfat on serum lipids and monocyte and platelet interactions with aortic endothelial cells. Atherosclerosis. 80 (3): 171179.

29.Kawasaki M., Miura Y., Funabiki, R., Yagasaki, K. (2010): Effects of Simultaneous Dietary Fish Oil Ingestion and Sulfur Amino Acid Supplementation on the Lipid Metabolism in Hepatoma-Bearing Rats with Hyperlipidemia. J. Nutritional Science and Vitaminology Vol. 56, No. 4 P 247-254

30.Jackson R., Tunton O., Morrisett J. and Gotto A. (1978): The role of dietary polyunsaturated fats in lowering cholesterol in man. Circ. Res. 42: 447-453.

31.Wong S., Nestel P. and Trimble R. (1983): The adaptive effects of dietary fish and safflower oil on the lipid and lipoprotein metabolism in perfused rat liver. Biochem. Biophys. Acta 742: 103-109.

32.Bravo E., Flora L., Cantafora A., De Luca V., Tripodi M., Avella M., Botham K.M. (1998): 
The influence of dietary saturated and unsaturated fat on hepatic cholesterol metabolism and the biliary excretion of chylomicron cholesterol in the rat. Biochim Biophys Acta. 1390 (2): 134-148.

33.Wong A., Chan D.C., Ooi E.M., Ng T.W., Watts G.F., Barrett P.H. (2013): Omega-3 fatty acid ethyl ester supplementation decreases very-low-density lipoprotein triacylglycerol secretion in obese men. Clin. Sci. (Lond), 13;125(1): 45-51.

34.Hassanali Z., Ametaj B.N., Field C.J., Proctor S.D., Vine D.F. (2010): Dietary supplementation of n-3 PUFA reduces weight gain and improves postprandial lipaemia and the associated inflammatory response in the obese JCR:LA-cp rat. Diabetes Obes. Metab. 12(3): 265.

35.Danforth E., Horton E., O'Connell and Uagenaku A. (1979): Dietary induced alterations in thyroid hormones metabolism during overnutrition. J. Clin. Invest. 64: 1336-1347.

36.Davidson M. and Chopra I. (1979): Effect of carbohydrate and noncarbohydrate sources of calories on plasma T3 concentration in man. J. Clin. Endocrinol. And Metab. 48: 577-581.

37.Chopra J., Solomon D., Chopra U., Wu S., Fisher D. and Nakamura Y. (1978): Pathways of metabolism of thyroid hormones. Recent Porg. Horm. Res. 43: 521.

38.Glade M. and Riimers T. (1985): Effects of dietary energy supply on serum thyroxin, T3 and insulin concentrations in young horses. J. Endocrin. 104: 93-98.

39.Gavin I. and Moeller M. (1983): The mechanism of recovery of hepatic T4-5- deiodinase during glucose in refeeding: role of glucagon and insulin. Metab. 32: 543-551. 